\title{
La gestión patrimonial desde la responsabilidad social
}

\author{
Oscar Navajas Corral* \\ Nebrija Universidad (España)
}

\section{Jesús Fernández Fernández**}

\begin{abstract}
Resumen: Desde que comenzó la crisis financiera a finales del año 2007, en países como España se ha ido generado una situación paradójica: por un lado, las medidas de austeridad han tenido como consecuencia el decaimiento de la vida cultural -institucional- pero, por otro lado, y ante esta carencia, han proliferado movimientos sociales impulsando acciones culturales y gestión del patrimonio. Una paradoja que tiene su explicación en el simple hecho de la toma de conciencia y de responsabilidad por parte de la sociedad civil con algo intrínseco a ella, la cultura, que no puede ser reducida a un mero producto de consumo. Se trata más bien de un bien común, que es tanto una forma de identificarse y de (con)vivir en un territorio, como una vía de resistencia frente a cualquier tipo de pensamiento único. En este artículo se presenta una de estas iniciativas hijas de la crisis, La Ponte-Ecomuséu, que está trabajando desde 2012 en áreas como la innovación social, la recuperación del patrimonio y la creación y producción científica y cultural de base participativa.
\end{abstract}

Palabras Clave: Gestión del patrimonio; Conciencia; Responsabilidad; Participación; Ecomuseo; Desarrollo.

\section{Social Responsibility in Heritage Management}

Abstract: Since the financial crisis began in late 2007, in countries like Spain a paradoxical situation has arisen: on the one hand, the austerity measures have led to the decay of cultural life as reflected in the official establishments but on the other, there has been a proliferation of social movements promoting actions to counteract this deficiency. This paradox is due to the heightened awareness and responsibility on the part of civil society to protect their different cultural identities as a central aspect of quality of life, something that creates community and resilience and not just a mere product to be consumed by tourists. In this article we present one such initiative, La Ponte-Ecomuséu, working since 2012 on innovative programs of social participation in the creative rehabilitation of heritage and new artistic creation.

Keywords: Heritage management; Awareness; Responsability; Participation; Ecomuseum; Development.

\section{Introducción}

La evolución de las políticas patrimoniales y museísticas en España con la llegada de la democracia a mediados de los años setenta ha pasado por dos etapas claramente diferenciados. Por un lado, un periodo identitario con la revalorización y exhibición de las identidades oprimidas durante el franquismo. Por otro, un periodo postmoderno caracterizado por la inmersión en las tendencias culturales y económicas globales (Azúar, 2008: 27-28). El patrimonio y los museos dejaban de ser lugares para custodiar o testimoniar nuestro pasado, para convertirse en espacios donde se debía explicar quiénes éramos; una necesidad de las generaciones de la Transición que se sentían "amenazadas» por la amnesia y la obsolescencia de los recuerdos y que encontraron en estas instituciones una comprensión a la nostalgia del pasado (Bolaños, 2008: 492-493).

\footnotetext{
* Nebrija Universidad (España); E-mail: oscarnavajascorral@gmail.com

** Investigador independiente; E-mail: info@laponte.org
} 
Esta simplificada división tiene una fecha clara de finalización, el final de la primera década del siglo XXI. La llegada de la crisis financiera en 2007-2008 afectó profundamente al sector cultural, como al resto de sectores. Es un hecho que los procesos de patrimonialización y musealización se ralentizaron, los presupuestos vieron mermadas sus dotaciones y aunque no podamos afirmar que se detuviesen los procesos culturales si que se generalizó cierto "pesimismo» que se dejó notar en la acción social y cultural del individuo y de las comunidades locales.

La sociedad en su conjunto, pero los profesionales dedicados a la cultura especialmente, hemos sido testigos en estos últimos años de la dialéctica controvertida entre los diferentes modelos de gestión y de financiación de las denominadas industrias culturales, una designación derivada de la postmodernidad en la que tiene cabida toda actividad cultural y patrimonial susceptible de entrar en la economía de mercado y en la sociedad de consumo. En otras palabras, es la forma en la que nuestro sistema social y económico consigue mercantilizar la cultura, entendiendo esta en su sentido antropológico.

Este sistema, en periodos de recesión como en el que hemos sufrido y en un país como el nuestro en el que el sector cultural vive de la "beneficencia» conlleva a que la financiación mengüe, forzando a que se busquen alternativas para la captación de recursos ¿Supone esto un inconveniente?, quizás solo uno -aunque sí que surgen muchas incertidumbres-, entender la cultura dependiendo del tipo de financiación, y que esto sea lo que marque los procesos de creación, de salvaguarda y, lo más peligroso, que indique las pautas de en qué medida sirven al presente y al futuro de la sociedad.

En el fondo, el debate sigue estando en los modos de uso de la cultura y del patrimonio. No sabemos si la palabra «uso» es la más acertada, al igual que hablar de consumo cultural, como planteaba Juan José Millás ${ }^{1}$, es un empobrecimiento de la dimensión del propio concepto de Cultura; o utilizar la expresión "Industria Cultural», que no hace más que señalar su visión mercantil, limitando el verdadero sentido que posee de transformar a la sociedad. En estas páginas queremos reflexionar sobre otros modos de entender la cultura y el patrimonio, desde la acción y la responsabilidad de la sociedad civil que es donde realmente se fundamenta ese demagógico y manipulado -políticamente- desarrollo social, cultural y económico.

No deseamos que estas afirmaciones queden en palabras producto de una reflexión crítica sobre la realidad, pesimista, que nos envuelve, fundamentada únicamente en planteamientos teóricos, sino que pretendemos contribuir con una visión pragmática y positiva sobre otros posibles caminos para la gestión de algo como la cultura y el patrimonio que es inherente al ser humano. Para ello, a parte de plantear los términos en los que se entiende la responsabilidad social en este campo, se presentará la experiencia de La Ponte Ecomuséu, en Asturias, donde se está desarrollando una acción comunitaria como forma de gestión cultural y patrimonial.

\section{La Cultura empieza en la conciencia.}

Es indudable que la evolución de las creaciones culturales del ser humano está ligada a la historia del patrimonio y de los museos; a la capacidad innata, casi obsesiva (Díaz Balerdi, 1994: 48), por coleccionar y reflejar en un microcosmos material la irremediable fugacidad del tiempo humano. Uno de los momentos que quizás más ha destacado de esta acción coleccionista se encuentre en el proceso revolucionario francés de finales el siglo XVIII, donde se inició un desarrollo de confiscaciones de bienes en manos de una minoría para legarlos a una mayoría; una de las causas fundamentales, junto con la Revolución Industrial, que provocaron la destrucción del sistema de herencia de la memoria colectiva. Este cambio de «propietarios» de los bienes, de la minoría a la mayoría, conllevó, por un lado, una descontextualización del lugar en el que se encontraban y, por otro lado, la profesionalización e institucionalización. Es decir, era necesario un lugar «neutro» que permitiese la conservación y el acceso de la población a esos bienes y, al mismo tiempo, la creación de una nueva "élite» que decidiesen qué es lo que es merecedor de permanecer ad infinitum y cómo va a ser presentado.

El espacio que reunía las mejores condiciones para este patrimonio era el museo, un lugar heredado de la legendaria Grecia para compartir y generar conocimiento. En realidad, un lugar alejado de nuestra concepción, en ocasiones simplista, de la institución museal. El problema es que ese espacio social y vivo, sin delimitaciones físicas ni adjetivos restrictivos y encasillados, se convirtió en un universo aparte, apto casi en exclusiva para aquellos con las competencias suficientes como para "apreciar» lo que en ellos se salvaguardaba. Los esfuerzos revolucionarios por despojar a una minoría del monopolio cultural y entregarlo al pueblo habían fracasado. De hecho, incluso hoy día, si nos fijamos en nuestra concepción del museo, fuera de tintes legendarios, se hace desde una visión global con referencia a una 
época histórica (la época preindustrial), a una parte del mundo (Europa) y a un sistema social y cultural (Burguesía) que ya ha desaparecido o evolucionado (Varine-Bohan, 1969: 49).

Pero, como en todo proceso de institucionalización siempre existe un proceso alternativo, contestatario. Numerosas experiencias poco a poco fueron marcando una evolución distinta en la gestión de los bienes culturales, sobre todo la de aquellos que no tenían sitio en los grandes museos nacionales. Ejemplos son Francia y el desarrollo de los museos cantonales que recogían la cultura popular, los museos al aire libre escandinavos o los propios Parques Nacionales Norteamericanos (Yellowstone, 1872) que ampliaron el universo de lo patrimonializable. El desarrollo de la Etnología y la Antropología durante el siglo XIX añadiría a la realidad museológica una novedad, el elemento vivo, la contemporaneidad (Sierra, 1994).

El gran salto se producirá en 1972 cuando una serie de profesionales (sociólogos, antropólogos, museólogos, etc.), movidos -paradójicamente- por el inmovilismo institucional y el desencanto social que desencadenaron, a su vez, los adoquines del mayo francés de 1968, se reunieran, al amparo de del Consejo Internacional de Museos (ICOM) y de la UNESCO, en la ciudad de Santiago de Chile. Esta reunión, que pretendía ser un análisis de los museos iberoamericanos, ha pasado a historia por ser uno de los grandes eventos mundiales sobre la gestión cultural, patrimonial y del territorio de las comunidades. Se manifestó que el patrimonio y la cultura en su sentido antropológico no eran únicamente una herencia que se debía conservar en vitrinas, sino algo que debía ser un activo para la propia sociedad.

En plena crisis petrolera y postindustrial de los años setenta países como Francia, Canadá, Portugal, EE.UU., Níger, México, Holanda, Noruega o Suecia, por mencionar algunos, van a crear instituciones culturales que fueran capaces de poner en valor un patrimonio en un estado de «olvido», utilizarlo como fuente de identidad comunitaria y territorial, y como motor de desarrollo económico. Algunos de los ejemplos más emblemáticos de estas iniciativas se pueden encontrar en la creación del Museo Nacional de Niamey, un museo al aire libre que pasó de recuperar únicamente el patrimonio material a preservar las técnicas tradicionales, el patrimonio oral e inmaterial e impulsar el contacto intercultural convirtiéndose en un espacio de participación comunitaria y eminentemente didáctico (Toucet, 1975: 35). Como nos recordará Hugues de Varine-Bohan (1993: 6) el museo fue creado por la gente común para la gente común. Otro de los ejemplos fue el Museo de Barrio de Anacostia, en Washington, donde se instaló un museo experimental, para sacar a la comunidad de la marginalidad (Kinard, 1985: 219). Una de las acciones que ha pasado a la historia de la Museología y que refleja el sentido de esta nueva institución fue la exposición de 1969 titulada, La rata, indeseada convidada del hombre. Una exposición que trataba un problema real del barrio y de la comunidad, la concienciación sobre los problemas de la insalubridad en las calles. Con esta acción la exposición se convertía en un medio de comunicación, una forma de reflejar un problema de la comunidad y, al mismo tiempo, de otorgarle soluciones. Los museo, dirá John Kinard, deben estar dispuestos a asumir riesgos y a convertirse en instigadores de Nuevas tendencias culturales y sociales. (...) debe estar al servicio de la comunidad entera. (...), debe ocuparse de los objetos, los documentos y la historia oral que nos permiten comprender mejor el presente y pueden ayudarnos a desarrollar una mayor conciencia de la historia y la identidad de la comunidad. [...] el estudio de los problemas actuales, cuando se aborda en una perspectiva histórica, puede dar a los hombres una mejor comprensión del sentido de sus propias vidas y servir de orientación para el futuro (1985: 218-223).

Por último, es interesante el ejemplo de la Casa del Museo de México. El Museo Nacional de Antropología de México, dependiente del Instituto Nacional de Antropología (INAH), era aclamado internacionalmente como uno de los proyectos más importantes de su tiempo (Cameron, 1992: 40). A parte de su innovadora arquitectura y de su programa museográfico dedicado a las grandes civilizaciones del territorio mexicano, el Museo fue creado con la máxima de servir a los escolares del país y favorecer sus sentidos identitarios y sus dignidades. Pero en 1969, Mario Vázquez, en aquel momento director adjunto del Museo, afirmaría que el Museo Nacional de Antropología no ha sabido funcionar como habíamos previsto... No está hecho para los verdaderos mexicanos, ni para las gentes del campo y menos para los escolares. A los adinerados y los bien educados de la ciudad les gusta mucho. Más aún el museo se ha convertido en la atracción turística más popular de México. Era necesario rendirse a la evidencia que había sido construido para una finalidad que no podia atender. Habiamos olvidado que los suelos de mármol son demasiado fríos para los pequeños pies desnudos (Cameron, 1992: 40). En 1973, Mario Vázquez iniciaba el proyecto comunitario denominado La Casa del Museo, con el objetivo de integrar el museo en la comunidad por medio de la participación y organización social, y en donde las temáticas abordadas en el museo respondieran a los intereses y necesidades de la propia comunidad (Méndez, 2008: 7). La Casa del Museo se extendió a varias colonias populares de la Ciudad de México durante ocho años como un apoyo a la solución de los problemas de las comunidades más desfavorecidas ${ }^{2}$. 
Todas estas iniciativas tenían en común premisas como: potenciar la función social del museo, pasar del objeto como constructor del patrimonio al sujeto como constructor de su patrimonio, y entender el museo como un medio y no como un fin. El museo institucionalizado tal como había evolucionado y como se entendía a nivel político, social y profesional era cuestionado como un museo: inútil, que estaba destinado a desaparecer (Varine-Bohan, 1979), innecesario (Hudson, 1989), peligroso (Lindqvist, 1987), una institución para la aculturación (Cameron, 1992), o un cementerio (Adotevi, 1971). Pero en el fondo no se estaba cuestionando tanto el Museo en sí, sino la libertad de decidir a cada comunidad cómo apropiarse de su memoria material e inmaterial y cómo denominar ese espacio en el que almacenarla, en el caso de que hubiera que denominarlo. Se trataba de recuperar la esencia de la creación cultural y la conservación patrimonial, el derecho a elegir la propia identidad.

Para el filósofo Bernard Deloche el hombre sin identidad, alienado o amnésico, es una suerte de "viajero sin equipaje», transparente y desarraigado. La identidad es aquella que forjamos por medio de la evolución personal, de las relaciones sociales y con nuestro territorio. La creación cultural y la recuperación del patrimonio es, por tanto, la construcción de la identidad individual y colectiva. Esta construcción también significa la construcción de la diferencia. Si por un lado rescatamos y conservamos piezas y/o artefactos y/o bienes llamémoslas ideas, costumbres, monumentos o tradiciones, por otro lado, queremos que esas huellas que hemos decidido que permanezcan nos hagan diferentes, «únicos», con respecto al Otro. La identidad existe porque existen otras identidades.

Hoy es necesario defender valores culturales que sean el resultado de una evolución histórica y que constituyan las señas de identidad de numerosas comunidades. La pregunta clave que debemos plantearnos es quién decide qué es lo que forma parte de la identidad colectiva, qué es lo verdaderamente relevante como para ocupar un puesto en el olimpo de la Identidad Cultural de una sociedad determinada. En esta cuestión tan general, que incluye lo macro y micro de los procesos de patrimonialización y musealización, entendemos que la sociedad civil ha tenido y tiene un papel fundamental.

\section{El sentido de responsabilidad con la gestión del patrimonio.}

Las políticas culturales y patrimoniales de diferentes gobiernos (locales, autonómicos o estatales) con las que con asiduidad somos inundados, y que se encuentran repletas de conceptos bienintencionados como: la cohesión social, la participación ciudadana, el beneficio social y cultural o la construcción de identidad; en gran medida son acciones dirigidas a una comunidad concreta que se limita a ser un ente activo de consumo, pero pasivo del proceso de planificación y gestión.

Es como si nos hubiésemos acostumbrado, como ciudadanos, a delegar nuestras responsabilidades sociales en aquellos que han sido elegidos (Varine-Bohan, 1991: 17-18). Como si el ser humano, y en este caso nos referimos al que vive en una sociedad de bienestar, desgastada y de consumo, hubiera olvidado que su realidad temporal está dividida entre el tiempo biológico, como aquel donde se realizan todas las actividades útiles a la vida física, y el tiempo obligado, como aquel en el que las acciones son impuestas a la vez por las necesidades biológicas, por intereses colectivos y por necesidades intelectuales y materiales. Con ambos se fragua el tiempo social (político) que es el que se usa para el desarrollo de la dimensión personal y la dimensión social, comunitaria.

Todo individuo, por supuesto, es libre de utilizar este tiempo en aquellas actividades o inactividades que le interesen, pero existe una vivencia comunitaria que le hace en cierta medida responsable de la actividad grupal. Como hemos apuntado más arriba esta «responsabilidad» social es delegada en otros individuos, pero se debe ser consciente de que esa delegación puede contraer el estatus de convertirnos en «objeto», alejándonos de nuestra esencia de «sujetos» participativos y comunitarios. Podría parecer incluso que existe un mundo en el que los profesionales de la cultura y del patrimonio, o de los museos, estuvieran, digamos, del lado de la manipulación (negativa o positiva) de la toma de decisiones; y en el otro lado los ciudadanos, los miembros de una comunidad, que quedan relegados, como entes pasivos, a los designios de estos primeros. Pero, lejos de ser una simple crítica discriminatoria, lo que queremos reflejar es la capacidad de acción, de iniciativa que tiene cada individuo y, fundamentalmente, el sentido de responsabilidad.

No debemos olvidar que las sociedades evolucionan en función de su historia. La imagen que emana de cualquier sociedad no es más que el reflejo de su memoria. El patrimonio es uno de esos testigos. Es una consagración "neutral» (recalcamos lo de «neutral») de un hecho pretérito. Una especie de objeto o manifestación sagrada que todos, o una gran mayoría, reconocen como relevante para la identidad de un grupo y que, por tanto, debe ser conservado y puesto a disposición de todo aquel que desee reconocerse en 
él. Toda el vocablo 'patrimonio aglutina en sí lo cultural, lo natural, lo inmaterial, lo material, con valor formal, histórico, de uso o simbólico (Ballart, 2002); y son portadores de significados imprescindibles para la supervivencia social y cultural de una comunidad, capaces de construir lazos de identidad únicos y fundamentales para el desarrollo futuro de la misma. Sus cualidades, variables y características, así como la propia definición mutan y, al mismo tiempo, tiene el poder de ser acumulativo: aunque sea un bien pretérito no pierde significado ni valor sino que se revaloriza continuamente y se ve enriquecido con las nuevas aportaciones contemporáneas.

El patrimonio entra así en una dicotomía que lo enlaza con su propia raíz etimológica y debate su sentido de propiedad entre los límites de lo público - de y para todos-, y lo privado. La herencia patrimonial puede ser un conjunto de propiedades personales y/o familiares pero también un conjunto de manifestaciones (materiales e inmateriales), en forma de bienes patrimoniales institucionalizados y/o reconocidos. La primera herencia se ha producido durante la historia del ser humano en todo núcleo familiar y nos ha llegado como una concepción individualista y con límites marcados por la propiedad privada. Este mismo sentido de herencia es el que propició en numerosas ocasiones un coleccionismo privado que, con el tiempo, se constituiría en la segunda forma de herencia, la pública3. En este punto, y esto es quizá lo más destacable, podemos recuperar las palabras de Iñaki Díaz Balerdi (2006: 17):

Cuando algo pertenece a todos -y eso es lo que pasa con el patrimonio institucionalizado, del cual todos somos, en principio, propietarios-, parece como si ese patrimonio no perteneciese a nadie. Habrá excepciones, claro está, pero la mayoría de la gente no investirá de significado propio algo que fue acumulado por otro, que otros conservan en lugares cargados de restricciones -cuando no ocultan, por ejemplo, en almacenes de museos-, y cuyos arcanos de inteligibilidad y goce distan de ser idóneos, al estar explicados y difundidos por otros en un lenguaje que tampoco ve como propio.

$\mathrm{Al}$ mismo tiempo que a lo largo de la historia hemos acumulado patrimonio y lo hemos transferido -aunque sea de forma simbólica en algunos casos- de manos privadas para engrosar el acervo de bienes patrimoniales de toda una sociedad; también hemos ido adquirido unos derechos y unos deberes. Conservarlo, respetarlo y transmitirlo a las generaciones futuras son los deberes que debe cumplir cualquier sociedad. La responsabilidad de que estos deberes se cumplan se delegan tradicionalmente en los profesionales capacitados para asumir dichas funciones, pero en realidad esta responsabilidad atañe también a todo individuo de un territorio. Como ciudadano de un territorio se es partícipe de un patrimonio colectivo. Su degradación, su mal uso, su reconocimiento, su simbolismo o su olvido son responsabilidad moral de cada miembro de la comunidad.

El Patrimonio en este razonamiento no es únicamente algo del pasado sino que su representación física y simbólica se mantiene viva por la contemporaneidad (presente) y a disposición de los usos en el futuro, es decir, como un capital para el desarrollo y la conciencia colectiva. Este trabajo de concienciación sobre el patrimonio global (integral) y su responsabilidad individual y comunitaria permite la sensibilización de esta última y la apertura hacia la Cultura Crítica (Rivard, 1987), hasta convertirse en la «memoria» de esa comunidad. El proceso o los procesos de patrimonialización son por tanto la forma en la que el individuo, y en grupo, una comunidad, toman conciencia de su territorio, de su cultura compartida y de su patrimonio heredado.

\section{Una experiencia: La Ponte Ecomuséu (Santo Adriano, Asturias).}

Santo Adriano es un territorio de apenas $22 \mathrm{Km}^{2}$ de extensión, muy montañoso, que, como tantos otros ubicados en la zona rural de Asturias, vio su realidad totalmente transformada con el cambio de paradigma socio-económico de finales del siglo XX. Desde entonces la demografía cayó en picado, con unos índices de natalidad negativos y una población envejecida. El sector primario se transformó hasta reducir la tasa de actividad a mínimos históricos. No hay industria, los centros fabriles más cercanos se han ido desmantelando, y la alternativa de los servicios se restringe a la hostelería y el turismo. En estas circunstancias el futuro de estos territorios como sujetos políticos está en entredicho.

Los cambios no solo afectaron a los datos demográficos y económicos. La sociedad agraria tradicional también se transformó definitivamente. Se puede decir que desde la década de los 60 han desaparecido definitivamente las comunidades campesinas del agro asturiano, como parte de un proceso ya iniciado en el s. XIX. El sentimiento comunitario apenas existe y el individualismo ha sustituido las formas de gestión cooperativa, redundando en un mayor distanciamiento intracomunitario y una mayor dependencia 
de "gestores» externos. Las "competencias» de las comunidades, reguladas tradicionalmente por el derecho consuetudinario, han sido adquiridas definitivamente por las administraciones locales a lo largo de los siglos XIX y XX. Por ello el principio de corresponsabilidad vecinal que tan implantado estaba (lo que es de todos debe ser cuidado por todos para legarlo a las generaciones futuras en buen estado) se ha perdido y ya no existe un sentimiento de propiedad compartida: lo comunitario o "comunal» se ha convertido en "público» y no es percibido como algo de todos, sino como una propiedad ajena, de la Administración, entendida como algo externo, distante, perteneciente a una comunidad «otra».

A este cuadro de crisis sistémica hay que sumar la actual coyuntura económica, que no ha hecho más que ahondar en los problemas que afectan a la zona rural, viéndose seriamente afectados los dos sectores que actualmente son la principal fuente de contratación: la hostelería y los ayuntamientos. Por un lado, la dependencia del turismo nacional ha hecho que en los últimos años se redujese considerablemente la renta percibida por los negocios del sector, por otro, la administración local no dispone de los recursos disfrutados en otras épocas de mayor bonanza. Así, nuestro particular trance histórico-estructural, se ve envuelto y dificultado más si cabe por la actual crisis global.

Como puede verse, la poca oferta laboral no requiere de perfiles altamente cualificados: peones municipales y camareros principalmente. En este contexto no existen muchas alternativas para las personas que se han formado en la educación superior, que se ven obligadas a emigrar, lo que plantea todavía más dudas sobre el futuro de estos territorios: ¿quién promoverá algún día el apremiante cambio?, ¿será posible hacerlo sin este importante capital humano?

En esta coyuntura tan desfavorable surge en 2011 el proyecto de La Ponte-Ecomuséu, como una forma de resistencia a las contradicciones del sistema descrito. El ecomuseo se concibe como una herramienta de trabajo que, partiendo del aprovechamiento de recursos patrimoniales, busca crear nuevas oportunidades de empleo en un sector, el de la gestión cultural y patrimonial, altamente subdesarrollado en las zonas rurales de Asturias (Alonso y Fernández, 2012).

La idea surge de un grupo motor local, constituido por gente joven que tiene una buena formación y se resiste, por un lado, a tener que abandonar su territorio, y por otro, a asumir un destino laboral precarizado, que no se corresponde con sus expectativas ni su cualificación. El proyecto se apoya en tres premisas claves:

1) La idea y la ejecución corren a cargo del propio grupo motor constituido jurídicamente en asociación (denominada La Ponte). Se plantea como proyecto ciudadano, autogestionado y no dependiente de ayudas públicas o privadas, al menos en su fase inicial. Se asume la idea de que el patrimonio cultural es un bien común, y como tal debe poder ser gestionado por las comunidades locales, que para ello deben también recuperar ese principio de corresponsabilidad, tanto en el aprovechamiento como en el cuidado de estos recursos. La idea que subyace en este proyecto es la de tratar el patrimonio cultural como algo propio, cuidarlo y presentarlo como tal. Para ello se establecen convenios de colaboración con titulares públicos y privados con el objetivo de crear un marco de relaciones en que poder desarrollar esta idea.

2) La colección que integra el ecomuseo es el patrimonio natural y cultural que se encuentra en el territorio (Santo Adriano), que cuenta con un repertorio muy variado y de calidad en este sentido (iglesia prerrománica de Tuñón, cuevas del Conde y abrigo de Santo Adriano, con arte parietal del Paleolítico superior, Monumento Natural de Las Xanas, patrimonio etnográfico, paisaje cultural, buena gastronomía, patrimonio inmaterial, etc.).

3) El objetivo del ecomuseo es crear una nueva "comunidad», una red de actores que no busca suplantar a otras realidades, entidades, administraciones, etc., actuales, sino convertirse en un espacio alternativo de desarrollo personal y comunitario, con el que estas otras realidades puedan además colaborar. Se entiende como «comunidad» no a una totalidad, sino a un grupo definido de actores que trabajan en torno a un proyecto de carácter colectivo que persigue, en este caso, fines sociales, culturales y económicos. Por todo ello definimos este proyecto como una «empresa social del conocimiento» (Fernández, Pérez y López, 2015; Fernández, Alonso y Navajas, 2015).

\section{Acciones y resultados de La Ponte-Ecomuséu}

Desde que nació la iniciativa, La Ponte-Ecomuséu ha mantenido acciones en tres ámbitos: Investigación, recuperación y valorización del patrimonio local, y difusión e interpretación del patrimonio.

En cuanto al primer punto, investigación, La Ponte-Ecomuséu surgió de un grupo de profesionales y académicos vinculados a las ciencias humanas, arqueología mayoritariamente. Una de las premisas 
era crear mantener proyectos de investigación sobre el territorio y el patrimonio local. Algunos de los más destacados son «el estudio de la evolución sedimentológica del Abrigo de Santo Adriano. Implicaciones para la cronología del arte paleolítico cantábrico»; «la Arqueología del campesinado medieval», vinculado al Grupo de Investigación en Arqueología Agraria con el apoyo del Plan Nacional de I+D del Ministerio de Ciencia e Innovación («La formación de los paisajes del Noroeste peninsular durante la Edad Media (Siglos V-XII)» Ref. HAR2010-21950-C03-03) y de la Junta de Castilla y León ("León en la Alta Edad Media: el territorio de Cea entre los siglos V al XII» Ref. LE302A11-1); o "Arqueología de un emplazamiento de la Edad del Bronce en Santo Adriano».

La actividad de investigación y de generación del conocimiento se lleva a cabo también por medio de la organización de las jornadas anuales sobre Patrimonio Cultural y mediante la participación en congresos nacionales e internacionales. Las últimas ediciones de las jornadas estuvieron dedicadas a la figura de los Paisajes Culturales como forma de gestionar el futuro de un territorio y a la Innovación social en la gestión del patrimonio cultural. En cuanto a los congresos, recientemente La Ponte-Ecomuséu ha sido parte activa del Programa Especial de Ecomuseos y Museos Comunitarios, celebrado durante la XXIV Conferencia General del Consejo Internacional de Museos en Milán; y de la organización de una sesión sobre Cultural Heritage and Social Innovation en el Eighth World Archaeological Congress (WAC), en Kioto.

Por último es de destacar la publicación anual que se edita desde La Ponte: Revista Cuadiernu: difusión, investigación y conservación del patrimonio cultural. El Cuadiernu es uno de los medios a través del cual se comparte La Ponte con la comunidad local, global y científica. Cuenta con un consejo científico asesor de expertos y todos los manuscritos recibidos pasan por un proceso de revisión por pares. Bajo la premisa de que la información científica debe llegar a todo el mundo, los contenidos de la edición se distribuyen bajo una licencia de uso y distribución Creative Commons Reconocimiento-Uso no Comercial 3.0 España (cc-by-nc 3.0). Además, la revista Cuadiernu está indexada en bases de datos como Dialnet y Latindex.

En cuento a la recuperación y revalorización del patrimonio, en la actualidad La Ponte-Ecomuséu cuenta con espacios con acceso restringido, por su titularidad y/o nivel de protección, como la casa campesina y hórreo (etnografía), la Iglesia de San Romano (arte románico), la Iglesia de Santo Adriano de Tuñón (arte prerrománico asturiano), el abrigo paleolítico de Santo Adriano (arte rupestre), o Cueva del Conde (arte rupestre); y elementos incluidos en las rutas culturales de acceso libre como los molinos hidráulicos, el puente medieval, el lavadero, las caleras, la arquitectura tradicional, las construcciones ganaderas de media y alta montaña, el Monumento Natural del Desfiladero de Las Xanas, los diferentes yacimientos arqueológicos y la minería de hierro (s. XIX).

En las III Jornadas sobre Patrimonio Cultural se realizó un estudio con la población de la localidad para conocer de primera mano qué conocimientos tiene esta sobre su patrimonio y recoger además opiniones acerca de su estado de conservación y su gestión. Con una metodología basada en la participación ciudadana (BiComún) los principales resultados que se obtuvieron reflejaban la necesidad de una intervención en la recuperación y puesta en valor del patrimonio local más allá de la Administración, la que consideraban insuficiente, y el deseo de que la población local participara en las acciones de conservación del patrimonio. Los vecinos consideraban que se les tendría que consultar o al menos informar a los habitantes del entorno sobre los bienes que la administración quieren proteger y de las mediadas a aplicar (Fernández Fernández, 2015: 129-131).

El trabajo de investigación y recuperación de La Ponte-Ecomuséu no está enfocado únicamente a salvaguardar el patrimonio material, sino que se realizan grandes esfuerzos por mantener el patrimonio inmaterial de la zona. Se ha creado un Aula de música y baile tradicional, que permite estudiar, mantener y transmitir este herencia local.

Finalmente es destacable la creación de un grupo de intercambio agro-alimentario que busca potenciar el conocimiento de los alimentos autóctonos, su gastronomía y facilitar la interacción entre consumidores y productores locales. Con ello se pretende contribuir modestamente a hacer sostenible la actividad de los pequeños agricultores que todavía mantienen formas tradicionales de cultivo y mejorar la calidad de vida de las personas que vivimos en el medio rural. Fomentar el consumo de productos agrarios locales es una forma de contribuir a que el conocimiento y las prácticas de las comunidades agrícolas tradicionales.

El tercer ámbito, la difusión e interpretación del patrimonio, desde La Ponte-Ecomuséu entendemos que se debe compartir y difundir todo aquello que se ejecuta y ponerlo a disposición de la sociedad. Se han creador talleres de Arqueología, con el objetivo de acercar esta disciplina por medio de la experiencia; itinerarios culturales que vertebran el patrimonio natural y cultural de Santo Adriano; e itinerarios didácticos, dirigidos a centros públicos y privados de Educación Primaria, Secundaria y Bachillerato. 
La Ponte-Ecomuséu cuenta también con una librería con publicaciones relacionadas con las diferentes temáticas que trabaja el Ecomuséu: historia, arqueología, etnografía, antropología, desarrollo rural, ecología, etc.; y desde donde se fomenta a pequeñas editoriales y otros colectivos.

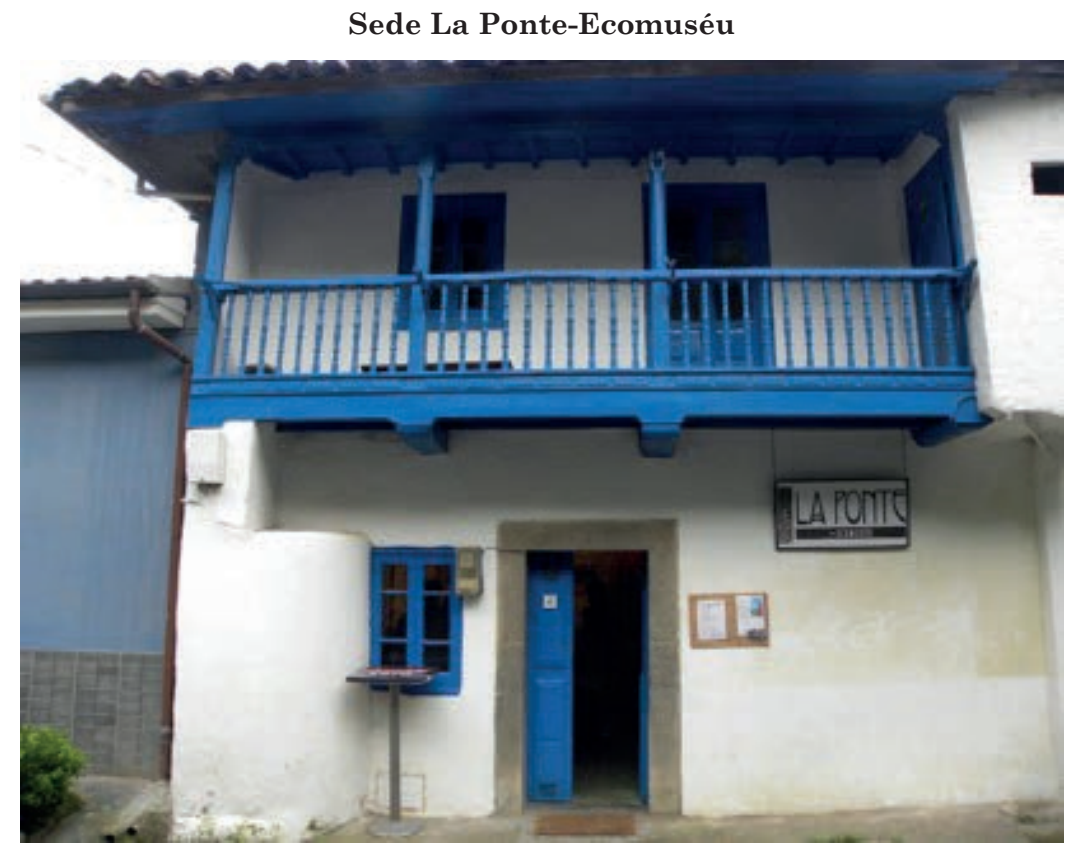

Fuente: La Ponte-Ecomuséu

En su primer año de funcionamiento generó cerca de mil visitas. Si se tiene en cuenta los modestos inicios presupuestarios de la iniciativa (menos de $100 €$ ) y los gastos derivados de las actividades organizadas, el balance fue positivo. Los beneficios hicieron posible disponer de recursos con los que crear la página web (www.laponte.org), material de difusión, la recuperación de un inmueble y su arquitectura tradicional, que más adelante conformaría la sede del ecomuseo4, y el primer contrato de trabajo. Pero La Ponte-Ecomuséu, como una «empresa social del conocimiento», parte de una gestión integral del patrimonio, buscando generar actividad económica, desarrollo, transferencia e innovación (Fernández, Alonso y Navajas, 2015). Esto supone que los resultados de la iniciativa no se midan por los datos que pueden generar las visitas o los ingresos. Su filosofía se encuentra en crear una comunidad inclusiva.

La Ponte-Ecomuséu se organiza por medio de asambleas donde se fijan principios comunes de actuación. Los diferentes grupos que se crean en cada asamblea trabajan en las áreas concretas del proyecto: investigación, didáctica, socialización, conservación, etc., que trabajan con autonomía de acuerdo a esos principios comunes. En esto años se han llegado a acuerdos con administraciones e instituciones (administración pública, Iglesia, etc.) para poder integrar todos los recursos patrimoniales dentro de un mismo proyecto; se han incorporado asociaciones, colectivos, profesionales, vecinos, colaboradores, etc.; pero la iniciativa no nació como una entidad que invitase a la participación sino como una iniciativa de la propia comunidad para transformar y crear una nueva comunidad. Su naturaleza civil y comunitaria hacen del proyecto una iniciativa que no responde a ningún interés institucional ni a una demanda administrativa.), donde se pretende jugar un papel protagonista de cara a la gestión como un bien común.

\section{Corresponsabilidad, patrimonio y participación. La experiencia de La Ponte-Ecomuséu y sus límites}

Un proyecto como el que se plantea parte de una idea fundamental: los ciudadanos asumen responsabilidades públicas voluntariamente con el objetivo de mejorar su situación socio-económica ¿Qué 
límites tiene una idea como esta en nuestro país? Hablamos de participación ciudadana, pero, ¿podemos participar? ¿Qué implicaciones puede/debe tener esta participación?

Según el Estudio European Mindset de la Fundación BBVA para 20105, el nivel de participación política y social en Europa es relativamente bajo en su conjunto, aunque presenta importantes matices entre países. El 34\% de los europeos llevó a cabo en 2010 alguna actividad de participación política y social (firma de peticiones, participación en manifestaciones, etc.). Suecia y Dinamarca alcanzaron los niveles más altos de participación cívica, más del 55\%, mientras que Bulgaria y Portugal, con menos del $20 \%$, ocuparon los últimos puestos en este ranking. España, con un $38 \%$ se sitúa ligeramente por encima de la media europea.

Respecto al asociacionismo, nuevamente las sociedades danesa y sueca demostraron ser las más implicadas (más del 70\% de la población encuestada declaró participar en alguna asociación, destacando con mucho la asociación sindical). Los países donde el asociacionismo mostró índices más bajos fueron Bulgaria, Polonia, Turquía o Grecia (con menos del 20\%). En España el 31\% declaró pertenecer a algún tipo de asociación.

Las siguientes preguntas que debemos formularnos son la siguientes: ¿es la no participación un asunto menor? ¿Qué implicaciones tiene para una sociedad?

La cuestión de la participación no es un asunto menor dentro de los problemas a los que nos enfrentamos las sociedades postindustriales, todo lo contrario, podríamos afirmar que el futuro de nuestra cultura del bienestar, que está ahora mismo en juego, solamente se salvará en aquellos lugares donde la ciudadanía se implique en los asuntos públicos. Quizá el mejor y más reciente ejemplo es el de la "revolución islandesa", sociedad que forzó la dimisión de un gobierno, sentó en el banquillo de los acusados a los responsables de la crisis y decidió por sí misma negarse en referéndum a aceptar las condiciones que se les querían imponer para el pago de la deuda acumulada por sus empresas bancarias. Todos los indicadores macroeconómicos muestran que los efectos de la actual crisis se han mitigado en este país. Su nivel de crecimiento actual no sería el mismo si la irresponsabilidad de la gestión financiera hubiese quedado impune, como en el resto de países del mundo, y las pérdidas privadas tuviesen que ser sufragadas por la sociedad entera "aquí y ahora", padeciendo recortes de servicios y derechos, tal y como ocurre en España, inmersa actualmente en una severa deriva institucional y social. Luego, como afirmábamos al principio de este párrafo, la participación no es una cuestión menor, de ella depende el bienestar colectivo.

Pero, ¿Es realmente posible que los ciudadanos podamos participar más? ¿Si en España se participa poco es porque no se quiere o porque no se puede? Volvamos de nuevo al caso concreto que estamos desarrollando aquí, relacionado con la gestión del patrimonio cultural en Asturias, para ir respondiendo a estas cuestiones.

Cuando nace el proyecto de La Ponte-Ecomuséu uno de nuestros principales dilemas es cómo plantear a la administración que una organización civil desea hacerse cargo de una parte del patrimonio cultural de su territorio del que aquélla administración es titular. Un patrimonio que se encuentra en muchos casos en un estado de semi-abandono, que no revierte en nada a las comunidades locales y que se pretende transformar en una fuente de actividad económica y desarrollo. En el proceso participativo sobre el conocimiento del patrimonio local que se realizó durante las III Jornadas con las con la población local, y que se comentó anteriormente, quedaba patente el deseo de la sociedad civil de involucrase en la toma de decisiones y en la salvaguarda del patrimonio de Santo Adriano (Fernández Fernández, 2015).

Por ello en primer lugar tuvimos que ir a la ley ¿qué posibilidades tenía propuestas de este tipo? ¿Era posible? El actual marco legal de referencia, a partir del cual se ha ido estableciendo el estatus jurídico de los bienes de interés cultural, es Ley de Patrimonio Histórico Español de 1985. Después cada comunidad autónoma ha ido aprobando sus respectivas normativas. Concretamente en el caso de Asturias se aprobó en 2001 la Ley 1/2001 de 6 de marzo de Patrimonio Cultural, según la cual, tal como se especifica en su Capítulo II, artículos 2 y 3, la administración podrá constituir diferentes acuerdos con entidades privadas sin ánimo de lucro para la gestión de los bienes integrantes del Patrimonio Cultural de Asturias que sean de titularidad pública. Vimos que el actual marco legal permitía una propuesta como la que planteábamos. El problema es que nuestra administración no está acostumbrada a recibir y gestionar este tipo de propuestas. Como veíamos la participación ciudadana y de las organizaciones civiles es en general escasa en España, pero concretamente en este ámbito de la implicación cívica en la gestión de bienes que son de titularidad pública casi podríamos decir que es anecdótica, al menos así lo era en 2011 cuando presentamos un primer borrador de proyecto. Más de un año tardó en ser evaluada nuestra iniciativa. Ni los mismos responsables y técnicos conocían precedentes jurídicos para establecer los acuerdos a los que hacen referencia los artículos anteriormente descritos de la Ley de 
Patrimonio, lo que hizo que en ocasiones se guiasen más por su opinión o criterio personal que por el marco legal, que como vimos era claro en este sentido. Finalmente se falló a nuestro favor y se estableció un precedente jurídico único en Asturias: una organización ciudadana se hacía cargo de la gestión de bienes declarados de interés cultural de titularidad pública.

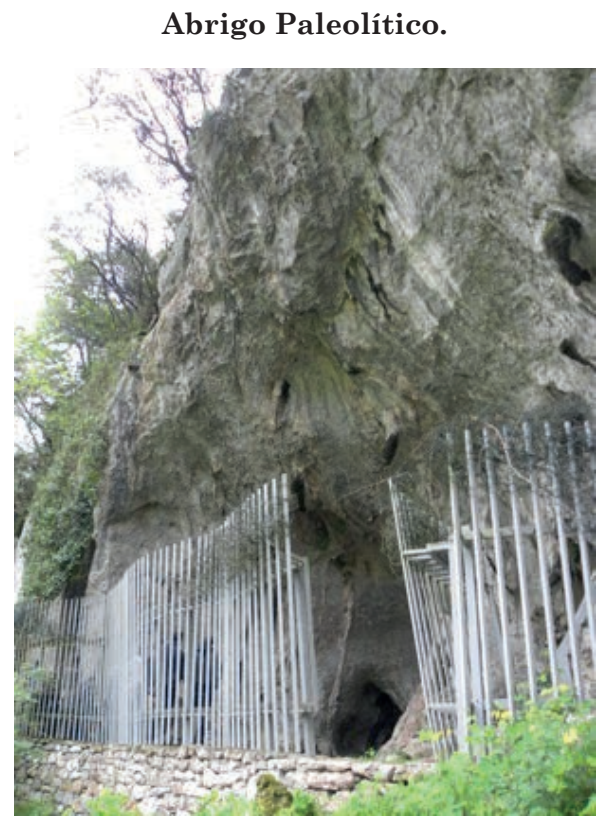

Fuente: La Ponte-Ecomuseu

Debemos apuntar que no es que el marco jurídico no permita por tanto la participación, sino que la ciudadanía no la reclama y la administración se encuentra ante dilemas que le exigen salirse de sus protocolos habituales y burocratizados, lo que a su vez implica la introducción de innovaciones administrativas y la toma de decisiones políticas. Por ello, esta participación, que en teoría es posible, no se practica y se fomenta poco por parte de unos administradores que muy a menudo se conforman con las cosas tal y como están. Como vimos en este apartado, esta toma de responsabilidad cívica no es un asunto menor, quedó demostrado con datos que allí donde no hay implicación de los "administrados» en los asuntos públicos, proliferan la falta de transparencia, la corrupción y en definitiva unos peores modelos de gestión de ese gran procomún que constituyen los bienes colectivos -entre los que se encuentra el patrimonio-, que son de todos/as y que deben ser gobernados por todos/as.

Pensamos que en la situación socioeconómica actual se ha evidenciado un desbordamiento de la capacidad del estado y las autonomías para cumplir con sus obligaciones con respecto al patrimonio cultural, cuya titularidad han ido acumulando. Los recursos humanos para su gestión, los técnicos y especialistas en patrimonio, son pocos frente a una pléyade de yacimientos, intervenciones, problemas de conservación y gestión, etc. Tanto más cuanto que el estado tiende a ser reducido por las políticas neoliberales de recortes. Un patrimonio que crece y un presupuesto que mengua. El caso es que no puede haber patrimonio sin la labor necesaria para su conservación. Si el patrimonio se abandona, se incumple el principio de puesta en valor, siempre presenten en las leyes que emanan de las propias administraciones. Es una tremenda contradicción.

Creemos que una solución futura ante esta situación es facilitar la gestión compartida de este patrimonio con organizaciones civiles que persigan fines sociales y con empresas del sector de la economía social. Para facilitar este proceso podría ayudar un cambio de definición del patrimonio, no como bien público, sino como bien colectivo, común. La diferencia es que el primero es del estado y la responsabilidad de su gestión recae exclusivamente en los cuadros de la administración. El segundo es de una «comunidad» que lo cuida y aprovecha, no sólo es público (compartido), sino que es común y eso obliga a establecer fórmulas consensuadas de gestión, abriendo la participación a más actores: la 
ciudadanía, a través de asociaciones, juntas de vecinos, fundaciones, cooperativas, etc. Este patrimonio es inalienable, como lo eran por ejemplo los montes comunales. De esta forma la renta que puedan generar siempre se reinvertirá en fines sociales y no lucrativos. Si hay un aprovechamiento será por parte de algún tipo de organización, fundación o comunidad local, que podemos aglutinar bajo la denominación de «empresas sociales de cultura y conocimiento». Por el contrario, la privatización de lo público, que es la solución que el actual programa neoliberal propone ante la crisis de deuda de los estados, da lugar a una explotación de recursos colectivos para fines puramente lucrativos, en los que las comunidades locales no suelen participar como sujetos activos. Hablamos aquí de las denominadas «industrias culturales», en las que la cultura es tratada como un mero objeto de consumo.

Los bienes de carácter colectivo permanecen vivos en la legislación actual. Por ejemplo, en la Constitución española se contempla, en su artículo 132, que la ley regulará el régimen jurídico de los bienes comunales, inspirándose en los principios de inalienabilidad, imprescriptibilidad e inembargabilidad. ¿Por qué el patrimonio cultural no puede regularse como un bien común? Ello podría contribuir a la creación de órganos de decisión política horizontales y democráticos, que cuenten con el apoyo en su gestión de diferentes agentes sociales e instituciones: técnicos de patrimonio, juristas, Iglesia, ciudadanía, etc. Consideramos que el patrimonio cultural ha de servir de base a este tipo de fines y no a los político-partidistas, que nos han llevado a los actuales modelos de gestión, muy ineficientes en gran número de casos, que han puesto parte de nuestro patrimonio en peligro, y que ante el empuje de las políticas neoliberales amenaza directamente con su venta o privatización.

Por todo ello creemos que es fundamental poner en marcha procesos de experimentación e innovación social como el que presentamos. El ecomuséu se constituyó como una "empresa social del conocimiento". "Empresa", porque se gestiona siguiendo una racionalidad económica. "Social", porque se basa en un modelo de gestión comunitaria y no persigue fines lucrativos. Y finalmente "del conocimiento" porque la ciencia y la tecnología son centrales en la definición del ecomuséu, ya que a través de él se busca aplicar y diseminar saberes previamente adquiridos en los campos de la Historia, la Arqueología, las ciencias del patrimonio, la Etnografía, o los saberes populares. La Ponte-Ecomuséu tiene por tanto los rasgos propios de un "laboratorio", (...) concebido, puesto en marcha y liderado desde una organización civil. Hablamos por tanto de tecnología e innovación, pero no de "base tecnológica", sino de "base social", ciudadana, anclada localmente y abierta. Se busca convertir de esta forma al patrimonio en el argumento central en torno al cuál poner en marcha todos estos procesos de innovación social (Fernández, Alonso y Navajas, 2015: 118). La Ponte-Ecomuséu no es al fin y al cabo más que un prototipo, que lejos de pretender convertirse en una forma hegemónica de hacer las cosas, sirve más bien como espacio de acción, discusión y reflexión, demostrando en cualquier caso que otras formas de hacer las cosas en la gestión patrimonial son posibles, más allá de las agendas políticas y las tutelas administrativas.

Acudimos al patrimonio por que estamos en crisis. En este caso el concepto de crisis es entendido como "falta de". Esta falta de algo es una persecución constante de lo que fuimos, de lo que fueron los que nos precedieron, y de la incesante búsqueda de la respuesta existencialista a qué hacemos en este mundo, sobre todo, en momentos como el actual en el que el "sistema establecido" se tambalea.

El patrimonio, los museos, la cultura en general, no son la respuesta pero sí que albergan todo aquello que la raza humana ha construido, y destruido. Albergan lo que decidimos ser y o dejar de ser. Miden el tiempo, recordando con exactitud todo lo que ha sucedido en nuestras vidas y a nuestro alrededor. Un disco duro infinito y acumulativo, con virus, que se puede borrar, pero en el que siempre cabe la posibilidad de hacer un backup. Y los lugares en los que se "almacena" o se pone en valor este banco de datos suplen la función memorística del ser humano. Palian lo efímero del pretérito en nuestras mentes dejando que nos apropiemos una y otra vez de él para que lo utilicemos en nuestro día a día, incluso en nuestro futuro.

Pero lo importante en todo esto, como intentamos pincelar en las palabras preliminares y en la experiencia de La Ponte Ecomuséu, es la intervención y el proceso de participación y responsabilidad individual y comunitaria, y no solo como ejecutantes sino en el propio proceso de planificación y de construcción de ideas, de iniciativas, de innovación.

Los procesos en los que trabajamos indagan en debates que no son nuevos. Desde los inicios de aquella museología contestaría y comunitaria en los años sesenta y setenta, se han producido numerosas corrientes en el campo de la cultura que ahondan en la capacidad y problemática de la participación gestión comunitaria de la cultura o de los bienes culturales. Y aunque es cierto que el discursos teórico, sobre todo el que ha hecho referencia a la Museología Social, se construyó desde la práctica, en la actualidad el camino ha sido inverso, llegando incluso a existir una "idealización" de los mismos como forma de desarrollar las comunidades de forma integral (García Hermosilla, 2009). En ellos ha entrado 
conceptos que en ocasiones se han llevado a la generalización o que se han convertido en variables poco cuantificables. Estamos hablando de: 'comunidad', 'desarrollo', la propia 'participación', etc.

La Ponte-Ecomuséu no ha sido, ni es, ajena a este debate. De hecho es parte intrínseca en su proceso como proyecto. La comunidad de Santo Adriano no es solo una, definida y cerrada, sino que como toda población está compuesta por numerosas comunidades. En los miembros de estas comunidades existen miembros que han mostrado una respuesta positiva y activa con el proyecto, como se ha descrito anteriormente, pero también coexiste con miembros que no la posen. Las diferencias de intereses y prioridades en el seno de una sociedad son la lógica de su propia construcción y evolución. El peligro es pretender que un proyecto como el que se ha descrito se convierta en un espacio uniforme y sin tensiones.

\section{A modo de reflexión final.}

De todo lo anterior se deduce que existe una clara distinción entre los procesos de patrimonialización y musealización que parten de "lo institucional" y aquellos que parten de la acción comunitaria. El primero se centra en el objeto y en la satisfacción de la visita. El segundo se focaliza en el sujeto y busca la repercusión de forma integral en territorio. El primero suele estar sustentada en un modelo de iniciativa y gestión vertical, mientras que el segundo está basado en la horizontalidad, en la iniciativa y la acción que parten de la concienciación comunitaria.

La iniciativa y la acción son las dos armas privilegiadas del desarrollo comunitario. La iniciativa no se encuentra en la toma de decisión de un programa intelectual y/o administrativo, sino que se trata de la iniciativa que surge de la comunidad para llevar a cabo una determinada propuesta para un desarrollo común. La acción es el momento o los momentos de movilización de la comunidad.

Como vimos en la experiencia de Santo Adriano, no se está planteando tanto un cambio de modelo, como una adecuación de la gestión a la(s) realidad(es) de cada territorio y un desarrollo de los marcos legales que ya existen.

Los momentos de bonanza económica y de "estabilidad" social favorecieron los procesos de patrimonialización (Prats, 2012), fundamentalmente aquellos que partían de arriba-abajo. Pero el momento en el que nos encontramos ha mostrado la ineficacia de esas políticas efímeras y efectistas, que ya fueron denunciadas por algunos y aplaudidas por muchos, despertando pensamientos que generan en la mayoría de los casos pavor, rechazo y recelo. En realidad no es más que un miedo al cambio en el sistema y a comprender que una misma realidad se puede abordar con puntos de vista diferentes.

El proceso de gestión patrimonial y cultural que defendemos, cuyo objetivo es contribuir a la transformación de una realidad por la propia comunidad, debe ser una liberación de la conciencia, la iniciativa y la creatividad de la comunidad, como de cada uno de sus miembros. Es un proceso de toma de confianza en sí mismos y de alfabetización en el sentido pedagógico de Paulo Freire (1967). Una liberación de la capacidad de observación y de dominio de los cambios que interviene en la sociedad en general y en la situación de la comunidad en particular. La comunidad puede juzgar por ella misma y tomar sus propias decisiones con responsabilidad.

Pero este camino no se realiza aislado y en soledad. La comunidad es el conjunto de agentes (de comunidades) que conviven en un territorio dado. Los poderes políticos, las entidades privadas, las instituciones, los movimientos asociativos civiles y los propios habitantes deben crear espacios de encuentro, para el diálogo, el debate y la confrontación. En este espacios es donde se fragua el sentimiento de identidad y donde se pueden hacer efectivas las responsabilidades sobre el patrimonio y la cultura, como las que se mostraban en las acciones llevadas a cabo por La Ponte Ecomuséu.

Y todo este sistema posee un pilar esencial que lo sustenta, la utopía. La utopía es la herramienta que permite la continua creatividad, la iniciativa y la acción cultural comunitaria. Es el motor que permite que la cultura no sea entendida como un bien de "consumo», sino como formas de vida6. Esta razón utópica (León, 2010: 326) no se debe conceptualizar como lo imposible, lo inalcanzable, sino que debe entenderse como el acto de búsqueda constante de las motivaciones humanas para transformar la realidad presente en un proceso de autorreflexión individual y comunitaria.

\section{Bibliografia}

Alonso González, P., Fernández Fernández, J.

2012. "Rural development and heritage commons management in Asturias (Spain): the ecomuseum of Santo Adriano", Journal of Settlements and Spatial Planning. Special issue dedicated to the International Conference Rural Space and Local Development. Vol. 2: 245-253. 
Alonso González, P.; Fernández, J.; Y Navajas Corral, O.

2014. "La Ponte-ecomuséu: una herramienta de desarrollo local basada en el patrimonio», en Actas del Congreso SOPA, Congreso Internacional sobre Educación y Socialización del Patrimonio en el Medio Rural. La Descomunal. Revista Iberoamericana de Patrimonio y Comunidad, año 1, vol. II septiembre de 2015. Pp. 117-130.

Adotévi, S.

1971. Le musée inversion de la vie (Le musée dans les systèmes éducatifs et culturels contemporains). En Desvallées, A (organizador). Bary, M. y Wasserman, F. (directores) (1992). Vagues: une anthologie de la nouvelle muséologie. Mâcon: Editions W. vol. 1, 1992: 119-138.

Bolaños, M.

2008. Historia de los Museos en España, Gijón: Trea.

Ballart, J.

2002. El patrimonio histórico y Arqueológico: valor y uso. Barcelona: Editorial Ariel Patrimonio.

Cameron, D.

1992. Les parques de marbre sont trop froids pour les petits pieds nus. En Desvallées, A (organizador).

Bary, M. y Wasserman, F. (directores) (1994). Vagues: une anthologie de la nouvelle muséologie. Mâcon: Editions W. vol. 2, 1994: 39-57.

Díaz Balerdi, I. (coord.)

1994. Miscelania museológica, Bilbao: Servicio editorial de la Universidad del País Vasco.

Díaz Balerdi, I

2006. «Museos y patrimonio: de la distancia retórica a la interlocución democrática». En Arrieta Urtizberea, I (ed.) (2006). Museo, memoria y turismo. Servicio Editorial de la Universidad del País Vasco. Universidad del País Vasco. Bilbao. Pp: 15-32.

Diego, E.

2014. "Cultura del cupcake». Publicado en El País, el 5 de enero de 2014. http://blogs.elpais.com/sin-titulo/2014/01/cultura-de-cupcake.html

Fernández Fernández, M.

2015. "Y esto, ¿pa qué val? El patrimonio de Santo Adriano visto por sus vecinos». En Revista Cuadiernu, $\mathrm{n}^{\circ}$ 3. Pp: $127-144$.

Fernández Fernández, J., Pérez Maestro, C., López Gómez, P.

2015. «La interpretación del patrimonio como herramienta para la comunicación e innovación social en la gestión del arte rupestre». XIX International Rock Art Conference IFRAO. Serie Arkeos, vol. 37, pp. 1811-1825.

Fernández Fernández, J., Alonso González, P, Navajas Corral, O.

2015. «La Ponte-Ecomuséu: una herramienta de desarrollo rural basada en la socialización del patrimonio cultural». La Descommunal. Revista iberoamericana de patrimonio y comunidad. Monográfico I. Vol. II. Proceedings 1st. international congress for heritage education and socialisation in rural areas. Pp. 117-130.

Freire, P.

1967. «La educación como práctica de libertad». Editorial siglo XXI, Méjico.

García Hermosilla, C.

2008. «El museo de territorio y sociedad, ¿una utopía? El caso del Museo Industrial del Ter», en Arrieta Urtizberea, I. (ed.): Participación ciudadana, patrimonio cultural y museos. Entre la teoría y la praxis, Bilbao: Servicio Editorial de la Universidad del País Vasco, pp. 75-94.

García Hermosilla, C.

2009. «Nueva Museología. De derrota en derrota hasta la victoria final. Reflexiones desde el día a día», en IGLESIAS GIL, J. M. (ed.): Cursos sobre Patrimonio Histórico, $n^{\circ} 14$. Actas de los XX Cursos Monográficos sobre Patrimonio Histórico, Santander: PUbliCan - Ediciones de la Universidad de Cantabria, pp. 339-352.

Hudson, K.

1989. Un museo innecesario. En Museum nº 162 (41-2): 114-116.

Kinard, J. R.

1985. «El museo vecinal: catalizador de los cambios sociales». En Revista Museum, 37 (4): 211-223.

Lindqvist, A.

1987. Le musée dangereux. En Desvallées, A (organizador). Bary, M. y Wasserman, F. (directores) (1994)

"Vagues: une anthologie de la nouvelle muséologie". Mâcon: Editions W. vol. 2, 1994: 220-223. 
Méndez Lugo, A

2008. «Mapa situacional de los museos comunitarios de México». Informe para la UNESCO.

Millás, J. J.

2013. «Un ataque político a las formas de vida». Publicado en El País el 26 de diciembre de 2013. http:// cultura.elpais.com/cultura/2013/12/25/actualidad/1387989932_163299.html

Prats, Ll

2012. «El patrimonio en tiempos de crisis». En Revista Andaluza de Antropología, nº 2. Recuperado el 12 de mayo de 2012. http://www.revistaandaluzadeantropologia.org/index.php/13-articulos/28-el-patrimonio-en-tiempos-de-crisis.html

Rivard, R.

1987. «Muséologie et cultures». En Actas del IV Taller Internacional del Movimiento para la Nueva Museología (MINOM). Molinos, Aragón (España). (documento SIGNUD, cota: 1987-005-03).

Sierra Rodríguez, X. C.

1994. «Museos etnográficos. Una reflexión desde el debate sobre el patrimonio cultural». En Identidad y fronteras culturales: Antropología y museística. Actas del II Congreso de Historia de la Antropología Española. Olivenza Badajoz, pp: 109-116.

Toucet, P.

1975. «El museo de Niamey. Espejo de todo un país». En Revista Mensual de la UNESCO "El Correo". Febrero 1975 Ano XXVIII: 32-35.

Varine-Bohan, $\mathrm{H}$.

1969. "Le musée au service de l'homme et du développement». En Desvallées, A (organizador). Bary, M. y Wasserman, F. (directores) (1992). "Vagues: une anthologie de la nouvelle muséologie”. Mâcon: Editions W. vol. 1, 1992: 49-68.

Varine-Bohan, $\mathrm{H}$.

1979. «Los Museos en el Mundo». (1979). Salvat Editores. Biblioteca Salvat de Grandes temas. Barcelona. Varine-Bohan, H.

1991. L’initiative communautaire. Recherche et expérimentation. Collection Museologia. Difusión Presses Universitaire de Lyon. Éditions W y MNES. Savigny-le-temple (Francia).

Varine-Bohan, $\mathrm{H}$.

1993. «L'avenir des musées des communautés locales». Conferencia impartida el 15 de octubre en el Universidad d'Utrech. Publicada por el Consejo de Europa en el informe Moderniser la réflexion sur les musées. Les Quatre premières conferénces annuelles du Prix européen du musée de l'anneé. Strasbourg, $1997: 5-12$.

\section{Notas}

1 Juan José Millás (2013). "Un ataque político a las formas de vida”. Publicado en El País el 26 de diciembre de 2013. http:// cultura.elpais.com/cultura/2013/12/25/actualidad/1387989932_163299.html

2 El alcance de esta experiencia y de la filosofía que se percibía en las políticas museísticas, patrimoniales y educativas mexicanas se verán reflejadas en otro de los proyectos que se iniciaba paralelo: el Programa de Museos Escolares, con la intención de crear un museo en cada escuela del país, fundamentado en la acción comunitaria y coordinado por los propios alumnos y profesores, integrándose así, museo y comunidad, dentro del sistema escolar. En 1983, el INAH aglutinaría ambas experiencias en el Programa para el Desarrollo de la Función Educativa de los Museos (PRODEFEM), coordinado por un equipo multidisciplinar (antropólogos, historiadores, psicólogos, arquitectos, pedagogos, biólogos, etc.). La herencia de ambas prácticas darán lugar a la base metodológica que desembocó en los museos comunitarios mexicanos y su red nacional que se definiría en 1993 (Méndez, 2008: 7-8).

3 Uno de los momentos claves de este coleccionismo, como se señaló al principio del artículo, se produjo con la llegada de la Ilustración en el siglo XVIII y con la posterior Revolución Francesa a finales de la centuria. En estos momentos es cuando el patrimonio pasa de las manos de unos pocos, a pertenecer a un "todos". La nacionalización e institucionalización del patrimonio supone la concienciación no de una acumulación selectiva de bienes, sino el reconocimiento de unos objetos como propios, característicos y diferenciadores de una sociedad.

4 El edificio es una casa tradicional de dos plantas y una cuadra-pajar anexa, con una distribución interior habitual en este tipo de construcciones: la cocina en la planta baja y las habitaciones, baño y balcón en la planta alta.

5 http://www.fbbva.es/TLFU/dat/np_european_mindset_3082010.pdf

6 Juan José Millás (2013). "Un ataque político a las formas de vida". Publicado en El País el 26 de diciembre de 2013. http:// cultura.elpais.com/cultura/2013/12/25/actualidad/1387989932_163299.html

Recibido:

$31 / 10 / 2015$

Reenviado:

$30 / 05 / 2018$

Aceptado:

$27 / 06 / 2018$

Sometido a evaluación por pares anónimos 